\title{
Invasive slug populations (Arion vulgaris) as potential vectors for Clostridium botulinum
}

\author{
Kristine Gismervik , Torkjel Bruheim', Liv M Rørvik², Solveig Haukeland ${ }^{3}$ and Ida Skaar ${ }^{\text {** }}$
}

\begin{abstract}
Background: Norwegian meadows, including those for silage production, are recently found heavily invaded by the slug Arion vulgaris in exposed areas. As a consequence, large numbers of slugs might contaminate grass silage and cause a possible threat to animal feed quality and safety. It is well known that silage contaminated by mammalian or avian carcasses can lead to severe outbreaks of botulism among livestock. Invertebrates, especially fly-larvae (Diptera), are considered important in the transfer of Clostridium botulinum type $\mathrm{C}$ and its toxins among birds in wetlands. C. botulinum form highly resistant spores that could easily be consumed by the slugs during feeding. This study aimed to determine whether Arion vulgaris could hold viable C. botulinum and enrich them, which is essential knowledge for assessing the risk of botulism from slug-contaminated silage. Slug carcasses, slug feces and live slugs were tested by a quantitative real-time PCR (qPCR) method after being fed $\cong 5.8 \times 10^{4}$ CFU C. botulinum type $\mathrm{C}$ spores/slug.
\end{abstract}

Results: Low amounts of C. botulinum were detected by qPCR in six of 21 slug carcasses with an even spread throughout the 17 day long experiment. Declining amounts of C. botulinum were excreted in slug feces up to day four after the inoculated feed was given. C. botulinum was only quantified the first two days in the sampling of live slugs. The viability of $C$. botulinum was confirmed for all three sample types (slug carcasses, slug feces and live slugs) by visible growth in enrichment media combined with obtaining a higher quantification cycle (Cq) value than from the non-enriched samples.

Conclusions: Neither dead nor live invasive Arion vulgaris slugs were shown to enrich Clostridium botulinum containing the neurotoxin type $C$ gene in this study. Slugs excreted viable $C$. botulinum in their feces up to day four, but in rapidly decreasing numbers. Arion vulgaris appear not to support enrichment of $C$. botulinum type $C$.

Keywords: Slug invasion, Clostridium botulinum, Botulism, Arion vulgaris, Bacterial vector, Silage contamination, qPCR

\section{Background}

Populations of the invasive slug Arion vulgaris (erroneously often referred to as $A$. lusitanicus) are spreading rapidly and invade gardens, vegetable crops and meadows including those for silage production [1-3]. Dense populations of more than 50 slugs per square meter have been recorded in wildflower strips and meadows [4]. As a consequence, large numbers of slugs might contaminate grass silage and cause a possible threat to animal feed quality and safety.

It is well known that silage contaminated by mammalian or avian carcasses can lead to severe outbreaks of

\footnotetext{
*Correspondence: ida.skaar@vetinst.no

${ }^{1}$ Norwegian Veterinary Institute, Pb 5695 Sluppen 7485 Trondheim/Pb 750

Sentrum, Oslo NO-0106, Norway

Full list of author information is available at the end of the article
}

botulism in livestock [5-7]. One contaminated carcass can be sufficient to cause the death of hundreds of cattle fed mixed rations [8] due to the highly potent neurotoxins (BoNT A-F) produced by Clostridium botulinum $[9,10]$. The neurotoxins block the acetylcholine release at the motor nerve-endings resulting in flaccid paralysis. Death is often caused by respiratory paralysis and circulatory failure. Despite the shared ability to produce neurotoxins, $C$. botulinum is a very heterogeneous species divided phylogenetically and physiologically into four different groups (I-IV). Group IV consists of Clostridium argentinense (previously named C. botulinum), known for BoNT $G$ production [10]. Type $C$ and D toxin producing strains of $C$. botulinum, belonging to group III, are considered the most common cause of animal botulism $[5,11]$. Of the other toxin producing strains (A, B, E 
and F) associated with human botulism [12], type A and B have been reported in bovine botulism outbreaks $[5,11]$.

C. botulinum produces highly resistant spores that are widely distributed in soil, dust, animal feces and aquatic environments $[9,13,14]$. Anaerobic conditions and a suitable growth medium are required for germination and toxin production. Some invertebrate carcasses can satisfy these requirements for $C$. botulinum growth [9,15]. In addition, invertebrates are not susceptible to the toxin and may even concentrate toxins when feeding on decaying carcasses. Fly-larvae (Diptera) feeding on decaying carcasses are considered important in the transfer of $C$. botulinum type $C$ and its toxins among birds in wetlands [15-17]. These highly toxic maggots perform cascades of intoxications when birds consuming maggots receive botulism and die. The carcasses attract flies for egg laying, resulting in an increase of toxic maggots that could lead to avian botulism epizootics [18]. Toxin laden maggots have been reported as a suspected source of botulism in ruminants, although other sources like vertebrate carcasses in drinking water could not be excluded $[19,20]$.

Invasive $A$. vulgaris slugs live in close contact with soil and have a wide diet feeding on various fresh and decaying plants but also animal excrements and waste including carcasses from both invertebrates and vertebrates [1]. Although prevalence studies are missing, the feeding habits of slugs make them quite likely to come in contact with and consume $C$. botulinum. This study aimed to determine whether slugs could hold viable $C$. botulinum and enrich them, essential knowledge for assessing the risk of botulism from slug-contaminated silage. After feeding slugs C. botulinum spores, slug carcasses, slug feces and live slugs were tested for $C$. botulinum.

\section{Materials and methods}

\section{Slugs}

In order to secure no presence of $C$. botulinum in the starting population, laboratory hatched $A$. vulgaris were used in the experiment. Eggs were collected in September 2012 from South-East Norway (Røresand), from a location with undisturbed vegetation and with no use of molluscicides. The eggs hatched in September and October at $16 \pm 2^{\circ} \mathrm{C}$. Slugs were kept in plastic containers on moistened tissue paper and fed sliced carrot, Chinese cabbage and a commercial piglet feed for protein enrichment (Format Kvikk 160, Felleskjøpet Agri, Norway). The feeding experiment started in April 2013. To ensure a fast ingestion of the inoculated feed, the slugs were starved $65 \mathrm{~h}$ prior to the onset of the feeding experiment. Slugs used in the experiment were on average $4.5 \mathrm{~g}$ (range 3.4-5.8 g). The $\mathrm{pH}$ of five scalpel chopped slugs, starved for $48 \mathrm{~h}$, was measured later on using $\mathrm{pH}$-indicator strips (Merck KGaA, Darmstadt, Germany).

\section{Spore production and quantification}

A spore suspension of C. botulinum type $C$ was produced by inoculating strain CCUG 7970 (Culture Collection University of Göteborg, Sweden) into eight tubes of $9 \mathrm{ml}$ freshly made tryptose-peptone-glucose-yeast extract (TPGY) broth (5\% Tryptone, Becton, Dickinson and company (BD), Sparks, USA, 0.5\% Proteose Peptone, BD, 0.4\% glucose, Merck, $2 \%$ yeast extract, BD, $0.1 \%$ starch, Merck, $0.1 \% \mathrm{~L}$-cystein- $\mathrm{HCl}$ and $0.14 \% \mathrm{NaHCO}_{3}$ ) [21]. The tubes were heated for $5 \mathrm{~min}$ at $70^{\circ} \mathrm{C}$ and incubated for one week at $37^{\circ} \mathrm{C}$ under anaerobic conditions (GENbag, bioMerieux, Marcy l'Etoile, France). The cultures were centrifuged and washed as described by Lindberg et. al. [22] to remove debris from the spore suspension. The spore suspension was stored at $4 \pm 2^{\circ} \mathrm{C}$ until use, and the viability and purity was determined by plating onto blood agar followed by both aerobic and anaerobic incubation at $37 \pm 1^{\circ} \mathrm{C}$ for $48 \mathrm{~h}$.

The enumeration of the spore suspension was conducted by plating two serial dilutions onto blood agar followed by incubation at $37^{\circ} \mathrm{C}$ under anaerobic conditions for $72 \mathrm{~h}$. The serial dilutions was frozen immediately at $-20^{\circ} \mathrm{C}$ in portions of one $\mathrm{ml}$ in $1.5 \mathrm{ml}$ tubes (Eppendorf AG, Hamburg, Germany) in order to create standard curves in quantitative real-time PCR (qPCR) as later described. The qPCR was used to quantify $C$. botulinum spores given each slug in the experiment. To test the accuracy, another serial dilution of the spore suspension followed by plating on blood agar as previously described was performed the first day of the experiment.

\section{Preparation of inoculated feed}

One $\mathrm{cm}$ thick discs of cucumber (Cucumis sativus) were sliced and kept in a refrigerator for $48 \mathrm{~h}$ to gain a more dry texture capable of some liquid absorption. Small quadratic pieces were prepared from the outer cucumber layer, with the bottom of each piece consisting of peel to prevent penetration of fluid. A small well was sliced by scalpel into each cucumber piece. To each $0.5 \mathrm{~g}$ piece of cucumber $0.04 \mathrm{ml}$ of the C. botulinum spore suspension was added. Slugs given one piece of inoculated feed received $\cong 5.8(\mathrm{SD} \pm 0.1) \times 10^{4} \mathrm{CFU}$ C. botulinum/ slug determined by qPCR, which was in agreement with the cultivation.

\section{The feeding experiment}

The experiment included a total of 67 slugs, where six served as negative controls and seven as reserve (Figure 1). Negative controls of slugs or slug feces were sampled on each day of analysis. The slugs were weighed individually both at the start of the experiment and when they were euthanized.

To collect individual samples, the live slugs were kept individually in boxes. The boxes were changed daily 


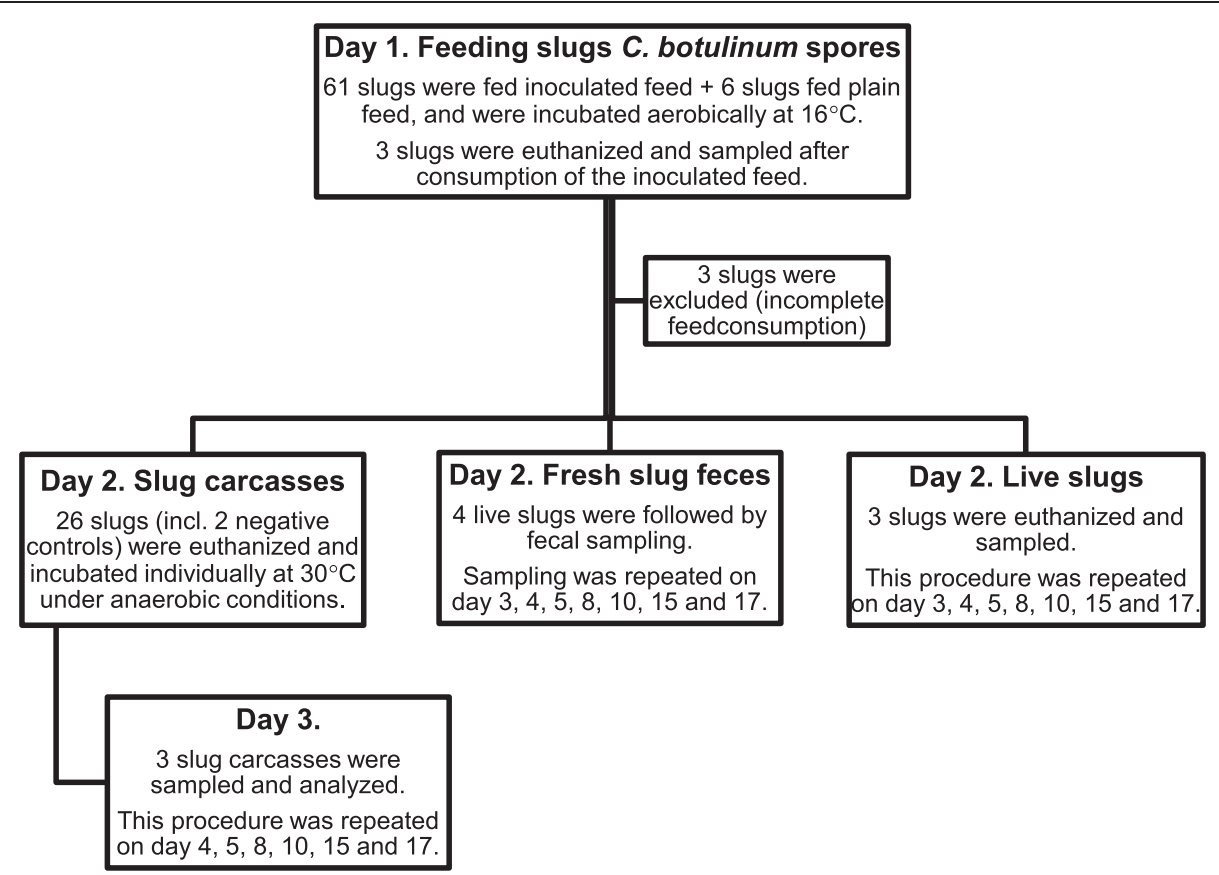

Figure 1 Overview of the 17 day long feeding experiment. Slugs were fed inoculated feed containing C. botulinum type C spores (or plain feed for negative controls) on day one, followed by sampling of slug carcasses, fresh slug feces and live slugs.

(except in weekends) to reduce the risk of recontamination from the slugs' own feces and mucus. The feed intake was monitored after 2,4 and $24 \mathrm{~h}$ and slugs with incomplete feed consumption after $24 \mathrm{~h}$ were excluded. From the second day, the slugs were fed white cabbage (Brassica oleracea convar. capitata var. alba).

A day rhythm of $8 \mathrm{~h}$ LED light was controlled by a timer. The temperature was maintained at $16 \pm 2^{\circ} \mathrm{C}$ throughout the experiment for the live slugs, to simulate a mean Norwegian summer temperature. An incubation temperature of $30 \pm 1^{\circ} \mathrm{C}$ was chosen for the slug carcasses. This temperature will support C. botulinum type $C$ growth $[5,22]$ and is relevant for newly made silage [23].

\section{Euthanizing of slugs and preparation of samples}

Prior to analysis, slugs were rapidly euthanized by making a sagittal cut with a scalpel between the cephalic tentacles to cut the nerve ring in the head region of the slug. Slugs were finely chopped by scalpel prior to dilution in saline peptone water (dilution rate 1:10). A dilution rate of 1:100 was necessary for the slug feces samples, due to small feces amounts. The diluted samples were homogenized by hand for 2-4 min in BagFilter's (Interscience, St Nom la Bretêche, France). One ml of each sample was transferred into $1.5 \mathrm{ml}$ tubes (Eppendorf AG). In addition, one $\mathrm{ml}$ was transferred to TPGY broth for enrichment. Inoculated TPGY broth was heated for $10 \mathrm{~min}$ at $70^{\circ} \mathrm{C}$ to eliminate growth of other than spore-forming bacteria before incubating at $30 \pm 1^{\circ} \mathrm{C}$ for $72 \mathrm{~h}$ in anaerobic conditions. The heating of the TPGY broth would kill also vegetative C. botulinum, but those would be detected by qPCR in the non-enriched samples. To rationalize, not all TPGYenriched samples were tested by PCR. Enriched samples from slugs and slug feces were only tested if the corresponding non-enriched sample yielded negative results and there was visible growth/gas-production in the TPGY broth. All samples were immediately frozen at $-20^{\circ} \mathrm{C}$ and stored for up to two months before analysis by PCR.

\section{Detection and quantification of $C$. botulinum type $C$ by PCR}

A real-time PCR assay detecting the BoNTC gene covering a chimeric $C / D$ sequence [24] was used [22]. The primers were $\mathrm{F}$ 5'-CACAAGAAGGATTTGGTGCTTTATCA-3' and R $5^{\prime}$-CAGACTTAGAAAATCTACCCTCTCCTACA$3^{\prime}$ and the MGB (Minor Groove Binding) probe $5^{\prime}$-CAT TACTATATGTTAGCATAAATCT-3' with 5' 6-FAM dye and a non-fluorescent quencher. The real-time PCR assay was made quantitative (qPCR) by generating a standard curve from the tenfold serial diluted and enumerated spore suspension of C. botulinum. The logarithm of the known initial concentrations plotted against the quantification cycle $(\mathrm{Cq})$ value gives a straight line, and forms the standard curve [25]. The $\mathrm{Cq}$ values obtained from unknown 
samples were then converted to estimated cell numbers by this standard curve and the use of a software (Bio-Rad CFX manager 3.0).

DNA was extracted using Qiagen BioSprint 15 Blood kit (Qiagen, Hilden, Germany) and KingFisher $\mathrm{mL}$ for magnetic based separation (Thermo, Helsinki, Finland). The samples were centrifuged at $16000 \times \mathrm{g}$ for $7 \mathrm{~min}$. An amount of reagents as described for $200 \mu \mathrm{l}$ of blood in the user manual was added to the sediments followed by the manufacturer's instructions. The extracted DNA was analyzed with CFX96 $6^{\text {min }}$ real-time PCR detection system (Bio-Rad Laboratories, Hercules, USA) or kept in a fridge at $4 \pm 2^{\circ} \mathrm{C}$ for $18 \mathrm{~h}$ before analysis. Each run included a negative extraction control and positive and negative controls, in addition to the samples and the serial dilutions forming the standard curve. All samples, standards and controls were run in triplicates. To be considered as positive, two out of three $\mathrm{Cq}$ values had to be below 40 . The qPCR mixture $(25 \mu \mathrm{l})$ consisted of $12.5 \mu \mathrm{l}$ LightCycler 480 Probes Master (Roche Diagnostics $\mathrm{GmbH}$, Mannheim, Germany), $0.45 \mu \mathrm{M}$ of each primer, $0.3 \mu \mathrm{M}$ of the fluorogenic probe (Applied Biosystems, Warrington, Great Britain), $0.25 \mu \mathrm{l}$ Uracil-N-glycosylase (UNG, $1 \mathrm{U} / \mu \mathrm{l}$, Eurogentec S.A., Seraing, Belgium), $6.25 \mu \mathrm{l}$ RNase-free water and $3 \mu \mathrm{l}$ of extracted DNA for testing. A multiplate 96-well format with adhesive sealing was used for the analysis (Bio-Rad).

\section{Statistics}

Statistical analysis was performed with the Stata version 12 software packages (StataCorp LP, Texas, USA).

\section{Results}

Six of 21 slug carcasses were positive for C. botulinum type $C$ without the need of TPGY enrichment. The amounts were stable during the whole period (Table 1).

C. botulinum type $\mathrm{C}$ was excreted in slug feces in declining numbers up to day four after the inoculated feed was given (Table 2). Cq values were markedly increased in enriched samples, proving viable C. botulinum (data not shown). Of the four slugs followed by fecal sampling, one slug was excluded due to producing too little or no feces for several days. Due to negative results, analysis of slug feces was terminated after day 8.

Live slugs were all positive for C. botulinum at day one, with a mean $\mathrm{Cq}$ of $36.0(\mathrm{SD} \pm 1.3)$ and a corresponding mean $\log$ CFU/g slug of 2.6 ( $\mathrm{SD} \pm 0.4$ ) for the three slugs. This gives a calculated CFU of $2.3 \times 10^{3}$ C. botulinum/ slug. At day two, one slug was positive and showed a mean $\mathrm{Cq}$ of $39.3(\mathrm{SD} \pm 0.94)$ and $1.7(\mathrm{SD} \pm 1.5)$ mean $\log$ $\mathrm{CFU} / g$ slug. The other two slugs were only positive after TPGY enrichment and with markedly increased $\mathrm{Cq}$ values. All live slugs tested negative during day 3-5. Figure 2 summarizes the mean quantification of $C$.
Table 1 Quantitative detection of C. botulinum in slug carcasses by qPCR

\begin{tabular}{cccc}
\hline Day & N positive & ${\text { Mean } \mathbf{C q}^{\text {a }} \text { (SD) }}$ & Mean log CFU/g (SD) \\
\hline 3 & 0 (of 3) & ND & ND \\
4 & 1 (of 3) & $39.15( \pm 0.72)$ & $1.4( \pm 1.1)$ \\
5 & 1 (of 3) & $38.39( \pm 1.01)$ & $1.7( \pm 1.5)$ \\
8 & 1 (of 3) & $38.97( \pm 0.63)$ & $1.6( \pm 1.2)$ \\
10 & 1 (of 3) & $39.79( \pm 0.05)$ & $1.3( \pm \cong 0)$ \\
15 & 0 (of 3) & ND & ND \\
17 & 2 (of 3) & $38.9( \pm 0.07)$ & $1.6( \pm 0.03)$ \\
\hline
\end{tabular}

${ }^{\mathrm{a}}$ Mean Cq represents the mean of the positively quantified samples. Each sample was run in three qPCR replicates. The corresponding mean log CFU/g was calculated from the standard curve.

qPCR, Quantitative real-time PCR.

Cq, Quantification cycle.

SD, Standard deviation.

CFU, Colony-forming units.

ND, Not detected; less than 2 replicates per sample yielded Cq values $<40$.

botulinum in the slug carcasses, slug feces and live slugs. The $\mathrm{pH}$ measured from each of the five chopped slugs was $\mathrm{pH} 7$.

\section{Standard curve and limit of detection}

The standard curves generated acceptable efficiencies of $95.2 \%, 104.1 \%, 95.4 \%$, slopes of $-3.4,-3.2,-3.4$ and $\mathrm{R}$ squares of $0.991,0.995$ and 0.990 . They included 5 points of dilutions in three replicates. The most diluted of $\cong 2.2 \mathrm{CFU} / \mathrm{ml}$ showed replicates with Cq values above 40. Consequently a spore concentration above $2.2 \mathrm{CFU} / \mathrm{ml}$ (or $0.34 \log \mathrm{CFU} / \mathrm{g}$ ) was needed to be detected by this method. Samples with mean Cq values of $\geq 39$ yielded SD above the recommended limit of 0.20 among replicates, which shows that the precision of quantification at such low levels is limited with this method. All negative control

Table 2 Quantitative detection of C. botulinum in slug feces by qPCR

\begin{tabular}{cccc}
\hline Day & N positive & ${\text { Mean } \mathbf{C q}^{\text {a }} \text { (SD) }}$ & Mean log CFU/g (SD) \\
\hline 2 & 3 (of 3) & $35.3( \pm 2.13)$ & $3.8( \pm 0.6)$ \\
3 & $1^{\text {b }}$ (of 3) & $38.5( \pm 1.01)$ & $2.9( \pm 0.7)$ \\
4 & $1^{\text {c }}$ (of 3) & $39.0( \pm 0.60)$ & $2.6( \pm 2.2)$ \\
5 & 0 (of 3) & ND & ND \\
8 & 0 (of 3) & ND & ND
\end{tabular}

${ }^{a}$ Mean Cq represents the mean of the positively quantified samples. Each sample was run in three qPCR replicates. The corresponding mean log CFU was calculated from the standard curve.

Additionally, $2^{\mathrm{b}}$ (or $1^{\mathrm{C}}$ ) other samples were positive after TPGY-enrichment (Cq not shown).

qPCR, quantitative real-time $\mathrm{PCR}$.

$\mathrm{Cq}$, quantification cycle.

SD, Standard deviation.

CFU, Colony-forming units.

ND, Not detected; less than 2 replicates per sample yielded Cq values $<40$. 


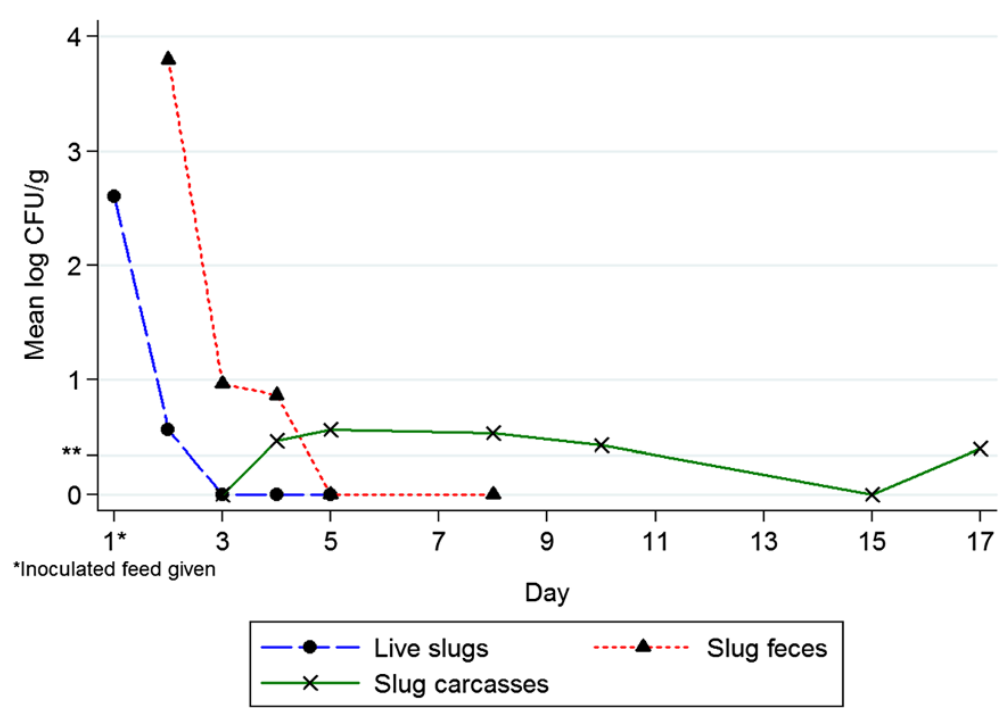

Figure 2 Mean C. botulinum quantification in slug carcasses, slug feces and live slugs by qPCR. Inoculated feed was given on day 1. The mean of three slug carcasses, three slug feces samples or three live slugs per day of analysis is included in the mean log CFU/g. Negative results are also included in the mean. ${ }^{* *}$ Detection limit $>0.34 \log$ CFU C. botulinum/g.

slugs in the feeding experiment and negative qPCR controls turned out negative for C. botulinum type C.

\section{Discussion}

Both dead and live A. vulgaris showed to be poor growth substrates for $C$. botulinum containing the BoNTC gene in this feeding experiment. Nevertheless, viable C. botulinum were excreted in slug feces up to day four after the inoculated feed was given and persisted in the slug carcasses during the whole experiment.

C. botulinum has a broad ability to use different types of animal and vegetable proteins as a growth substrate $[9,13]$. In addition, colonization of the intestine is reported in infants, young animals and under special conditions also human and animal adults $[5,9,10]$. Surprisingly, our experiment showed that neither slug carcasses nor live slugs supported enrichment from the C. botulinum spores fed to the slugs. The bacterial number measured by this qPCR method is limited to the fraction of C. botulinum with intact BoNTC gene. This gene, located on a bacteriophage, can be lost during cultivation [26,27]. Still, visible growth or absence of growth in the TPGY broth supported the GPCR results, leaving no evidence of major gene-loss.

C. botulinum type $\mathrm{C}$ has a minimum growth temperature of $15^{\circ} \mathrm{C}$. Although an optimum temperature of $40^{\circ} \mathrm{C}$ is reported, good growth conditions at $30^{\circ} \mathrm{C}$ are described [5,22]. A water activity over 0.98 and $\mathrm{pH}$ over 5.4 (terrestrial strains) or 5.1 (marine strains) are needed. These key parameters of growth were assumed fulfilled in our experiment, as measured from the five chopped slugs showing a $\mathrm{pH}$ of 7 . James et. al. calculated mean
$\mathrm{pH}$ in crop fluids from seven Black slugs (A. ater) to be $6.41 \pm 0.33$ (SE) [28]. Differences in the $\mathrm{pH}$ of the digestion system of starved and fed Gray (field) garden slug (Deroceras reticulatum) are reported, but all values were between $\mathrm{pH} 6$ and 7 [29].

Germination of endospores is considered to be one of the most important limiting steps of C. botulinum enrichment [26]. The germination is still poorly understood and is triggered by complex interactions of nutrients, nonnutrients, enzymes and physical stimuli. Ensiling grass may add factors that might stimulate $C$. botulinum growth from contaminated slugs, given spots in the silage with interrupted $\mathrm{pH}$ decrease, but that was not investigated in the present study. Differences in the spore germination are seen between the four C. botulinum groups, but also individual strains within the same group show variability [26]. Thus, other C. botulinum strains may give different results than obtained in our experiment. On the other hand, C. botulinum is known to be a weak competitor in rich bacterial cultures like the intestinal microflora [30], and enrichment might have been inhibited by the bacterial flora of $A$. vulgaris. Slugs such as the closely related $A$. ater, and the keeled slugs Limax maximus, Deroceras reticulatum and snails such as Cornu aspersum and Helix pomatia are known to have a rich intestinal microflora. Bacteria belonging to Enterobacteriaceae, enterococci, lactobacilli and Clostridium spp. (none defined as C. botulinum) are among others reported from these slugs and snails [31-34]. In Sweden amounts of 5.4 log CFU/g of lactic acid bacteria and $6.0 \mathrm{log}$ CFU/g Enterobacteriaceae are reported from A. vulgaris merged with slug feces and some grass residues [35]. Several intestinal 
bacterial strains, among them lactobacilli and enterococci, are reported to have bacteriostatic effects on C. botulinum [36-38].

Our experiment showed that slugs excreted viable $C$. botulinum type $\mathrm{C}$ in feces up to four days after orally being given a calculated amount of $\cong 5.8(\mathrm{SD} \pm 0.1) \times 10^{4} \mathrm{CFU}$ C. botulinum/slug. The three slugs analyzed on day one showed that $2.3 \times 10^{3} \mathrm{CFU} /$ slug was successfully detected after feeding, a tenfold decrease compared to the given amount. The main reason of this difference was probably leakage of the spore suspension to the environment, since the slugs consumed the feed themselves. Low numbers of C. botulinum could be detected in slug carcasses during the entire period of testing. There was no evidence of enrichment. Hence the risk of classical botulism caused by BoNTC from slug contaminated silage would be considered low. Still, the actual effects of slugs into grass silage remain to be investigated. Well-preserved silage is protected by a pH below the growth limits of undesirable microorganisms like C. botulinum. However, an acidic pH will not destroy preformed neurotoxin [39]. The BoNT carrier status of $A$. vulgaris slugs feeding on contaminated carcasses would therefore be of interest. Fifteen of 37 aquatic snails collected on or close to avian carcasses tested positive for type $C$ toxin with titers of $50-1600$ mouse minimum lethal doses/g. None of 19 snails without the carcass association tested positive [15]. Slugs' carrier status of BoNT is also relevant since slugs might be grazed directly. If slugs only hold a low spore contamination, without pre-formed BoNT, they would not be considered a greater risk to consume than feed from the already contaminated environment. The impact of large numbers of adult $A$. vulgaris slugs in preservation processes in silage remains to be investigated [35].

\section{Conclusions}

Neither dead nor live invasive A. vulgaris slugs enriched C. botulinum containing the BoNTC gene in this study. Slugs excreted viable $C$. botulinum in feces up to four days after fed $C$. botulinum spores, but in rapidly decreasing numbers. A. vulgaris appear not to support C. botulinum type $\mathrm{C}$ enrichment.

\section{Abbreviations \\ BoNT: Botulinum neurotoxin; CFU: Colony-forming units; Cq: Quantification cycle; TPGY: Tryptose-peptone-glucose-yeast extract broth; \\ qPCR: Quantitative real-time polymerase chain reaction. \\ Competing interests \\ The authors declare that they have no competing interests.}

\section{Authors' contributions}

KG carried out the feeding experiment with establishment of $\mathrm{qPCR}$, analysis and drafted the manuscript. TB, LMR and IS participated in the design of the study and contributed to the manuscript. TB was also involved in discussions of GPCR methods and results. SH was involved in the management of the slugs from hatching to the start of the experiment and contributed to the manuscript. All authors read and approved the final manuscript.

\section{Acknowledgements}

The Research Council of Norway; Foundation for Research Levy on Agricultural Products and Agricultural Agreement Research Found is acknowledged for funding the Ph. D. studentships of K.G. Thanks to Pundharika Barkved and Margrete Vigerust at the Norwegian Veterinary Institute and Hanna Skarin at National Veterinary Institute Sweden for discussions and help with establishing the qPCR method. Arild Andersen at Norwegian Institute for Agricultural and Environmental Research, Ås, Norway is acknowledged for collecting the A. vulgaris eggs, together with Karin Westrum at the same institute, and contributing in design with his great knowledge of slugs.

\section{Author details}

${ }^{1}$ Norwegian Veterinary Institute, Pb 5695 Sluppen 7485 Trondheim/Pb 750 Sentrum, Oslo NO-0106, Norway. ${ }^{2}$ Norwegian University of Life Sciences, School of Veterinary Science, Pb 8146 dep, Oslo NO-0033, Norway. ${ }^{3}$ Norwegian Institute for Agricultural and Environmental Research, Fr. A. Dahlsvei 20, Ås NO-1430, Norway.

Received: 5 April 2014 Accepted: 9 September 2014

Published online: 03 October 2014

\section{References}

1. Kozlowski J: The distribution, biology, population dynamics and harmfulness of Arion lusitanicus Marbille, 1868 (Gastropoda: Pulmonata: Arionidae) in Poland. J Plant Prot Res 2007, 47:219-230.

2. Ewaldz T, Von Proschwitz T, Jönsson B: Bekämpning av sniglar i lantbruk och yrkesmässig trädgårdsodling. Jordbruksverket: Jönköping; 2008.

3. Hatteland BA, Roth S, Andersen A, Kaasa K, Støa B, Solhøy T: Distribution and spread of the invasive slug Arion vulgaris Moquin-Tandon in Norway. Fauna Norv 2013, 32:13-26.

4. Briner T, Frank T: The palatability of 78 wildflower strip plants to the slug Arion lusitanicus. Ann Appl Biol 1998, 133:123-133.

5. Lindström M, Myllykoski J, Sivela S, Korkeala H: Clostridium botulinum in cattle and dairy products. Crit Rev Food Sci Nutr 2010, 50:281-304.

6. Wilkinson J: Silage and animal health. Nat Toxins 1999, 7:221-232.

7. Driehuis F, Oude Elferink SJ: The impact of the quality of silage on animal health and food safety: a review. Vet Q 2000, 22:212-216.

8. Galey FD, Terra R, Walker R, Adaska J, Etchebarne MA, Puschner B, Fisher E, Whitlock RH, Rocke T, Willoughby D, Tor E: Type C botulism in dairy cattle from feed contaminated with a dead cat. J Vet Diagn Invest 2000, 12:204-209.

9. Quinn P, Carter M, Markey B, Carter G: Clinical veterinary microbiology. London: Mosby; 1994.

10. Hatheway CL: Toxigenic clostridia. Clin Microbiol Rev 1990, 3:66-98.

11. Böhnel H, Gessler F: Diagnosis of botulism since. Report of test results. Berl Munch Tierarztl Wochenschr 1995, 2003(116):269-273.

12. Lindstrom M, Korkeala H: Laboratory diagnostics of botulism. Clin Microbiol Rev 2006, 19:298-314.

13. Long SC, Tauscher T: Watershed issues associated with Clostridium botulinum: a literature review. J Water Health 2006, 4:277-288.

14. Kruger M, Grosse-Herrenthey A, Schrodl W, Gerlach A, Rodloff A: Visceral botulism at dairy farms in Schleswig Holstein, Germany: prevalence of Clostridium botulinum in feces of cows, in animal feeds, in feces of the farmers, and in house dust. Anaerobe 2012, 18:221-223.

15. Duncan RM, Jensen WL: A relationship between avian carcasses and living invertebrates in the epizootiology of avian botulism. J Wildl Dis 1976, 12:116-126.

16. Shayegani M, Stone WB, Hannett GE: An outbreak of botulism in waterfowl and fly larvae in New York State. J Wildl Dis 1984, 20:86-89.

17. Reed TM, Rocke TE: The Role of Avian Carcasses in Botulism Epizootics. Wildlife Soc B 1992, 20:175-182.

18. Wobeser G: Avian botulism-another perspective. J Wildl Dis 1997 33:181-186.

19. Wobeser G, Baptiste K, Clark EG, Deyo AW: Type C botulism in cattle in association with a botulism die-off in waterfowl in Saskatchewan. Can Vet J 1997, 38:782

20. Swift PK, Wehausen JD, Ernest HB, Singer RS, Pauli AM, Kinde H, Rocke TE, Bleich VC: Desert bighorn sheep mortality due to presumptive type $C$ botulism in California. J Wildl Dis 2000, 36:184-189. 
21. Skarin H, Lindberg A, Blomqvist G, Aspan A, Baverud V: Molecular characterization and comparison of Clostridium botulinum type $\mathrm{C}$ avian strains. Avian Pathol 2010, 39:511-518.

22. Lindberg A, Skarin H, Knutsson R, Blomqvist G, Baverud V: Real-time PCR for Clostridium botulinum type $C$ neurotoxin (BoNTC) gene, also covering a chimeric C/D sequence-Application on outbreaks of botulism in poultry. Vet Microbiol 2010, 146:118-123.

23. Kjus O, Randby A: Ensilage of grasses in round balers. Experiments at Hellerud [Norway] 1986. LT1-Trykk 1987, 68:20-22.

24. Takeda M, Tsukamoto K, Kohda T, Matsui M, Mukamoto M, Kozaki S: Characterization of the neurotoxin produced by isolates associated with avian botulism. Avian Dis 2005, 49:376-381.

25. Arya M, Shergill IS, Williamson M, Gommersall L, Arya N, Patel HR: Basic principles of real-time quantitative PCR. Expert Rev Mol Diagn 2005, 5:209-219.

26. Peck MW: Biology and genomic analysis of Clostridium botulinum. Adv Microb Physiol 2009, 55:183-265. 320.

27. Sakaguchi Y, Hayashi T, Kurokawa K, Nakayama K, Oshima K, Fujinaga Y, Ohnishi M, Ohtsubo E, Hattori M, Oguma K: The genome sequence of Clostridium botulinum type $\mathrm{C}$ neurotoxin-converting phage and the molecular mechanisms of unstable lysogeny. Proc Natl Acad Sci U S A 2005, 102:17472-17477.

28. James R, Nguyen T, Arthur W, Levine K, Williams D: Hydrolase ( $\beta$-Glucanase, a-Glucanase and Protease) activity in Ariolimax columbianus (Banana slug) and Arion ater (Garden slug). Comp Biochem Physiol B Biochem Mol Biol 1997 118:275-283.

29. Walker AJ, Miller AJ, Glen DM, Shewry PR: Determination of $\mathrm{pH}$ in the digestive system of the slug Deroceras reticulatum (Muller) using ion-selective microelectrodes. J Mollus Stud 1996, 62:387-390.

30. Burr DH, Sugiyama $\mathrm{H}$ : Susceptibility to enteric botulinum colonization of antibiotic-treated adult mice. Infect Immun 1982, 36:103-106.

31. Elliott $L$ : Certain bacteria, some of medical interest, associated with the slug Limax maximus. J Invertebr Pathol 1970, 15:306-312.

32. Shrewsbury J, Barson G: A contribution to the study of the bacterial flora of Arion ater. Proceedings of the Society for Applied Bacteriology 1947, 10:70-76.

33. Wilkinson PG: Characterisation of the bacterial flora associated with the grey field slug Deroceras reticulatum and assessment of its suitability as a target for biological control, PhD thesis. University of Edinburgh: Biological Sciences thesis and dissertation collection; 2011.

34. Charrier M, Fonty G, Gaillard-Martinie B, Ainouche K, Andant G: Isolation and characterization of cultivable fermentative bacteria from the intestine of two edible snails, Helix pomatia and Cornu aspersum (Gastropoda : Pulmonata). Biol Res 2006, 39:669-681.

35. Spörndly R, Haaga C: Silage quality when the crop is infected with Arion lusitanicus. In Nordic Feed Science Conference; 22-23 June 2010; Uppsala, Sweden. Swedish University of Agricultural Sciences: Department of Animal Nutrition and Management; 2010

36. Sullivan NM, Mills DC, Riemann HP, Arnon SS: Inhibition of growth of Clostridium botulinum by intestinal microflora isolated from healthy infants. Microb Ecol Health Dis 1988, 1:179-192.

37. Okereke A, Montville TJ: Bacteriocin-mediated inhibition of Clostridium botulinum spores by lactic acid bacteria at refrigeration and abuse temperatures. Appl Environ Microbiol 1991, 57:3423-3428.

38. Kruger M, Shehata AA, Schrodl W, Rodloff A: Glyphosate suppresses the antagonistic effect of Enterococcus spp. on Clostridium botulinum. Anaerobe 2013, 20:74-78.

39. Siegel LS: Destruction of botulinum toxin in food and water. In Clostridium botulinum Ecology and Control in Foods. Edited by AHW H, KL D. New York, USA: Marcel Dekker Inc; 1993:323-341.

doi:10.1186/s13028-014-0065-z

Cite this article as: Gismervik et al: Invasive slug populations (Arion vulgaris) as potential vectors for Clostridium botulinum. Acta Veterinaria Scandinavica 2014 56:65.

\section{Submit your next manuscript to BioMed Central and take full advantage of:}

- Convenient online submission

- Thorough peer review

- No space constraints or color figure charges

- Immediate publication on acceptance

- Inclusion in PubMed, CAS, Scopus and Google Scholar

- Research which is freely available for redistribution

Submit your manuscript at www.biomedcentral.com/submit
() Biomed Central 